\title{
The Effect of Hydrated Calcium Silicate Powder on the Three Main Indexes of Asphalt
}

\author{
CHENG Zhaoxia $^{1, \mathrm{a}}$, WAN Changli ${ }^{1, \mathrm{~b}}$, CHEN Jinming ${ }^{1, \mathrm{c}}$ and NIU Zhihui ${ }^{1, \mathrm{~d}}$ \\ ${ }^{1}$ School of Civil Engineering, Henan Polytechnic University, Jiaozuo, China, 454000 \\ achengzx@foxmail.com, ${ }^{\text {b457423687@qq.com, }{ }^{c} 615356590 @ q q . c o m, ~}{ }^{\mathrm{d}}$ niuzhihuiliang@qq.com
}

\begin{abstract}
The ball mill and the organic modifier were used to modify the powder of hydrated calcium silicate. Then the modified powders were characterization by oil absorption value, IR, SEM etc. Hydrated calcium silicate powders modified before and after were added to the asphalt and the three major indexes of asphalt were tested. The results show that the oil absorption activities of calcium silicate powder decrease obviously, the oil absorption value decreased $80 \%$. IR spectra show that the hydrated calcium silicate powder adsorbed on the surface modifier, the modified powder morphology was changed. With the increase of powder content, the penetration increases, the ductility decreases. The softening point of asphalt mixed with unmodified powder increases with the increase of powder mixed with modified powder asphalt softening point of $4 \%$ to reach the maximum, and then began to decrease.
\end{abstract}

\section{Introduction}

To improve the asphalt performance and meet the requirements of high grade highway, in the asphalt adding modified material and preparation of modified asphalt is a commonly used method, which polymer, mineral fillers and additives is commonly modified material ${ }^{[1-3]}$. Polymer, such as SBS and SBR, significantly improve the performance of asphalt, but the cost is high ${ }^{[4,5]}$. Modified asphalt additive effect, but its collocation rule is complex, the current development and application is not enough. Inorganic mineral filler, low cost, wide source, easy processing, has been widely used in engineering. The diatomite ${ }^{[6]}$, carbon black $^{[7]}$, volcano ash, fly ash ${ }^{[8]}$ and other solid waste application has shown good economic and social benefits.

Hydrated calcium silicate powder $(\mathrm{CSH})$ is the extraction of a new type of powder material, the industrialization process of aluminums prepared in high alumina fly ash non-toxic tasteless, white color, fine particles, porous. The CSH in the paper, rubber ${ }^{[9]}$ and other fields ${ }^{[10]}$ has made an initial exploration results show that $\mathrm{CSH}$ can be used as inorganic filler materials, but the application in modified asphalt has not been reported.

\footnotetext{
* Corresponding author:chengzx@foxmail.com
} 
Since asphalt filled with inorganic powder materials based on the hydrated calcium silicate filler has superior performance, the influence of calcium silicate hydrate on asphalt performance will be explored. The polarity of hydrated calcium silicate inorganic powder is very large, directly applied to the asphalt matrix will appear uneven dispersion, so this paper studied the unmodified and modified powder effect on asphalt performance. Powder milling is an important technology of preparation, surface treatment and organic modification. It is a simple method, good modification effect and high efficiency. The CSH as the object of study by planetary ball mill and silicon coupling agent modified of hydration calcium silicate powder, and the modified powder is added into the asphalt, the performance changes before and after the modification of powder and change before and after the powder to asphalt penetration, extended the influence of degree and softening point.

\section{Experiment}

\subsection{Experimental Raw Material and Equipment}

Activity of calcium silicate, Datang International Chemical Technology Research Institute, the average particle size of $29.9 \mathrm{~m}$, specific surface area $0.414 \mathrm{~m} 2 / \mathrm{g}$; silicon coupling agent, Chongqing Jia Shi Tai Chemical Factory, industrial grade; phthalate phthalate dioctyl fat, analysis of pure. Asphalt, AH-70\#, in the laboratory stored for 5 years.

\subsection{Sample Preparation}

Preparation of Modified Hydrated Calcium Silicate Powder

$20 \mathrm{~g}$ Hydrated calcium silicate are placed in the agate pot of the ball mill and adding modifier, in ball mill speed settings modified for a certain period of time , then the organic hydrated calcium silicate samples can be obtained.

Preparation of Modified Asphalt

When the asphalt was heated to a certain temperature, the powder is added into the asphalt container, stirring constantly to make it uniform.

\subsection{Performance Test}

Oil hydrated calcium silicate powder test according to analysis method for calcium carbonate. Infrared spectra were measured using 5DX FTIR Fourier transform infrared spectrometer; using FESEM Fei NOVA400 scanning electron microscope observation of the morphology of the powder; using a penetrometer tests penetration, extension of tester ductility, softening point tester test softening point.

\section{Experimental Results and Discussion}

\subsection{Oil Absorption Value of Hydrated Calcium Silicate Powder}

The oil absorption value is an important index to characterize the powder hydrophobic effect. Influence factors of the oil absorption value of the surface state of powder particle size, etc. The powder after ball milling, the pore structure of powder reduced the density increased; the particle size is reduced to a key role in the decline of oil absorption value. $1 \%$ modifier 
can have dispersed on the powder, hinder the agglomeration, reduces the oil absorption value, the oil absorbing powder of low value will be $80 \%$.

\subsection{Analysis of Hydrated Calcium Silicate Powder Infrared Spectroscopy}

Fig. 1 is the infrared spectrum before and after the hydrated calcium silicate powder modified. From Fig. 1, we can see that modified powder body curve than Original powder more absorption at $2852 \mathrm{~cm}^{-1}, 2921 \mathrm{~cm}^{-1}$ peak, which is the $-\mathrm{CH}_{3}$ and $\mathrm{CH}_{2}$ characteristic absorption peaks, indicating that the powder adsorbed on the organic modifier molecules.

Fig. 1 in hydrated calcium silicate curves $3448 \mathrm{~cm}^{-1} \mathrm{OH}$ symmetric stretching vibration peak, $1640 \mathrm{~cm}^{-1}$ for $\mathrm{H}_{2} \mathrm{O}$ bending in the peak, $667 \mathrm{~cm}^{-1} \mathrm{SiO}_{4}$ bending absorption peak modified are shifted to lower wavenumber region; hydrated calcium silicate curve in 1424 $\mathrm{cm}^{-1}, 967 \mathrm{~cm}^{-1}$ asymmetric stretching of the peaks and $448 \mathrm{~cm}^{-1} \mathrm{SiO}_{4}$ bending absorption peak modified after shifted to higher wave numbers.

The asymmetric stretch increases, in-plane bending decreases. This is because the mechanical force of the particles of the powder surface plastic deformation, lattice of particles produced dislocation defects and powder surface without stereotypes and change the vibration frequency of the $\mathrm{Si}-\mathrm{O}$ bond.

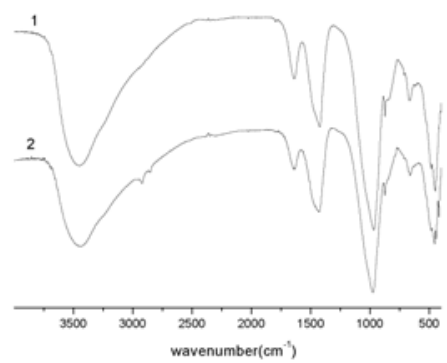

Fig. 1 IR spectra of Hydrated calcium silicate powder(1: Original powder;2: modified powder)

\subsection{Morphology Analysis of Hydrated Calcium Silicate Powder}

Fig. 2 shows the SEM before and after the hydrated calcium silicate powder modified. From the figure, it can be seen that, change of powder close to spherical, particle size uniform, surface honeycomb pore structure. The modified powder is a frustum shape or a cuboid shape, particle diameter size difference is bigger, the surface is no cellular holes, powder surface was translucent oil substance.
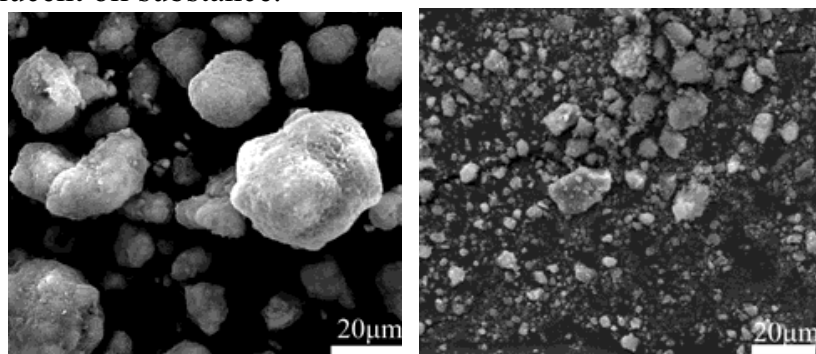

(a) Original powder (b) Modified powder

Fig.2 SEM of different scales before and after the Hydrated calcium silicate powder modified 


\subsection{Effect of Powder on the Three Indices of Asphalt}

Fig. 3 Effect of powder on the three indicators of asphalt. Where Fig.3(a) is the penetration of changes with powder admixture map. From Fig.3(a) we can see that with the increase of powder content, asphalt penetration increases. In the same dosage conditions, improve the penetration of asphalt powder after the more obvious. This is because the modifier for organic matter, and change the sheet structure of powder surface disappeared after. Therefore, the powder and asphalt more easily together.

The effect of Fig.3(b) for ductility. With the increase of powder dosage, reduce the degree of extension had different degree. Among them, the unmodified powder of asphalt ductility decreased more obviously. This is because the unmodified powder surface is flaky and pupil shape and surface properties of inorganic matter, hindering the pitch chain segment movement, in the tensile process, combination of powder and asphalt is not good, and more easily tearing.

Fig.3(c) is the effect of softening point. The unmodified and modified powder on the influence of different softening point of asphalt. The unmodified powder, with dosage increase, $2 \%-6 \%$ content from the softening point, continue to increase. The modified powder effect on the softening point of asphalt, $2 \%-4 \%$ is increased $4 \%$, increased to $6 \%$ began to decrease. This is because the surface of powder as the organic modifier, when the modified powder amount increases, organic matter powder surface increases, the equivalent of asphalt oil content increased. Therefore, the softening point will be increased first and then decreased.

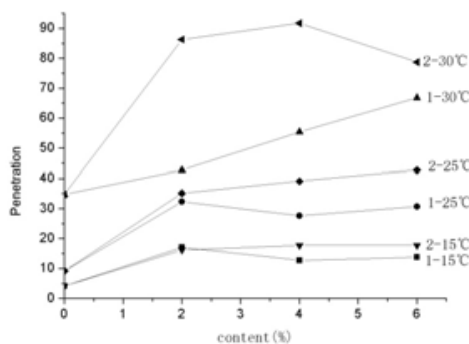

(a) Effect of powder dosage on penetration

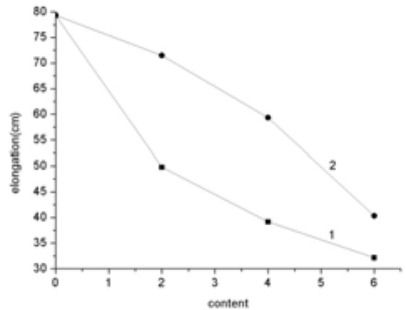

(b) Effect of powder content on the ductility

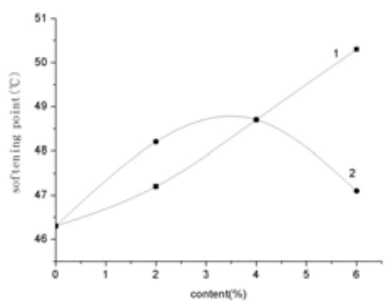

(c) Effect of powder content on the softening point

Fig.3 Effect of powder dosage on the three indices of asphalt (1: Original powder;2: modified powder)

\section{Summary}

1 After hydrated calcium silicate powders were modified, its morphology was changed, surface porosity and oil absorption value decreased.

2 Hydrated calcium silicate powders can increase the penetration of the asphalt and modified powder to asphalt penetration increased more effective than original powder. 
3 Original hydrated calcium silicate powders can reduces the ductility of asphalt more than modified powder.

4 The softening point of asphalt modified by original powder has been increased continuously, while the softening point of asphalt which modifier is modified powder is firstly increased and then decreased.

\section{Acknowledgments}

The study is supported by the National Students' Innovation Training Program (201410460010).

\section{References}

1. Akisetty, C.K., S.-J. Lee, and S.N. Amirkhanian, High temperature properties of rubberized binders containing warm asphalt additives, Construction and Building Materials. 23 (2009) 565-573.

2. You, Z., et al., Nanoclay-modified asphalt materials: Preparation and characterization, Construction and Building Materials.25 (2011) 1072-1078.

3. Hınıslığlu, S. and E. Ağar, Use of waste high density polyethylene as bitumen modifier in asphalt concrete mix, Materials Letters. 58 (2004) 267-271.

4. Zhang, F. and J. Yu, The research for high-performance SBR compound modified asphalt,Construction and Building Materials.24 (2010) 410-418.

5. Tayfur, S., H. Ozen, and A. Aksoy, Investigation of rutting performance of asphalt mixtures containing polymer modifiers, Construction and Building Materials. 21 (2007) 328-337.

6. Cong, P., S. Chen, and H. Chen, Effects of diatomite on the properties of asphalt binder, Construction and Building Materials. 30 (2012) 495-499.

7. Yamaguchi, K., L. Sasaki, and S. Meiarashi, Mechanism of asphalt binder aging by ultraviolet irradiation and aging resistance by adding carbon black,Journal of the Japan Petroleum Institute. 47 (2004) 266-273.

8. Xie, J., et al., Influence of surface treated fly ash with coupling agent on asphalt mixture moisture damage,Construction and Building Materials, 30 (2012) 340-346.

9. Peng, X.-Q., et al., The preparation study of the vulcanization accelerator silicone rubber,Gongneng Cailiao/Journal of Functional Materials. 41 (2010) 1820-1822+1826.

10. Peng, X., et al., Effects of the C-S-H powder on the hydration process and mechanism of cement,Jianzhu Cailiao Xuebao/Journal of Building Materials. 18 (2015) 195-201. 